\title{
Dual effects of fibroblast growth factor 21 on hepatic energy metabolism
}

\author{
Ricardo J Samms ${ }^{1}$, Michelle Murphy, Maxine J Fowler, Scott Cooper, Paul Emmerson', \\ Tamer Coskun', Andrew C Adams', Alexei Kharitonenkov², Francis J P Ebling \\ and Kostas Tsintzas
}

School of Life Sciences, Queen's Medical Centre, University of Nottingham, Nottingham NG7 2UH, UK ${ }^{1}$ Lilly Research Laboratories, Indianapolis, IN, USA

${ }^{2}$ Chemistry Department, College of Arts and Sciences, Indiana University Bloomington, 800 East Kirkwood Avenue, Bloomington, IN 47405-7102, USA

\begin{abstract}
The aim of this study was to investigate the mechanisms by which fibroblast growth factor 21 (FGF21) affects hepatic integration of carbohydrate and fat metabolism in Siberian hamsters, a natural model of adiposity. Twelve aged matched adult male Siberian hamsters maintained in their long-day fat state since birth were randomly assigned to one of two treatment groups and were continuously infused with either vehicle (saline; $n=6$ ) or recombinant human FGF21 protein ( $1 \mathrm{mg} / \mathrm{kg}$ per day; $n=6)$ for 14 days. FGF21 administration caused a $40 \%$ suppression $(P<0.05)$ of hepatic pyruvate dehydrogenase complex (PDC), the ratelimiting step in glucose oxidation, a $34 \%$ decrease $(P<0.05)$ in hepatic acetylcarnitine accumulation, an index of reduced PDC flux, a 35\% increase $(P<0.05)$ in long-chain acylcarnitine content (an index of flux through $\beta$-oxidation) and a $47 \%$ reduction $(P<0.05)$ in hepatic lipid content. These effects were underpinned by increased protein abundance of PD kinase-4 (PDK4, a negative regulator of PDC), the phosphorylated (inhibited) form of acetylCoA carboxylase (ACC, a negative regulator of delivery of fatty acids into the mitochondria) and the transcriptional co-regulators of energy metabolism peroxisome proliferator activated receptor gamma co-activator alpha (PGC1 $\alpha$ ) and sirtuin-1. These findings provide novel mechanistic basis to support the notion that FGF21 exerts profound metabolic benefits in the liver by modulating nutrient flux through both carbohydrate (mediated by a PDK4-mediated suppression of PDC activity) and fat (mediated by deactivation of ACC) metabolism, and therefore may be an attractive target for protection from increased hepatic lipid content and insulin resistance that frequently accompany obesity and diabetes.
\end{abstract}

Correspondence should be addressed to $K$ Tsintzas Email kostas.tsintzas@ nottingham.ac.uk

\section{Introduction}

Fibroblast growth factor 21 (FGF21) is an endocrine member of the fibroblast growth factor superfamily that plays a key role in the regulation of carbohydrate and fatty acid metabolism (Kharitonenkov \& Adams 2014).

\author{
Key Words \\ - FGF21 \\ - energy metabolism \\ - Siberian hamster \\ - adiposity
}

- liver
The primary physiological role of FGF21 is reported to occur during the adaptive response to starvation in rodents (Markan et al. 2014). Hepatic-derived FGF21 has been shown to function in an endocrine manner to 
facilitate hepatic fatty acid mitochondrial delivery, $\beta$-oxidation and subsequently ketone body production (Badman et al. 2007, Potthoff et al. 2009, Markan et al. 2014). In accordance with this, the administration of recombinant human FGF21 to animal models of obesity and diabetes was shown to confer clear metabolic benefits, including lowering of plasma glucose and insulin concentrations, improved blood lipid profiles and significant body weight reduction (Kharitonenkov et al. 2005, Coskun et al. 2008, Adams et al. 2012). Consequently, FGF21 is now being evaluated as a potential treatment for both obesity and diabetes and their associated comorbidities (Gaich et al. 2013, Gimeno \& Moller 2014).

The Siberian hamster (Phodopus sungorus) is a natural animal model of adaptive adiposity, which can be experimentally induced via a change in photoperiod to increase or decrease appetite and body weight (Ebling 2014). Their summer state is induced by long day lengths and is characterized by increased adiposity coupled with leptin resistance and elevated plasma insulin concentrations. In the winter short day lean state, the animals exhibit reduced plasma leptin concentrations and wholebody fat mass (specifically abdominal white adipose tissue). Furthermore, it has been demonstrated that these changes in the winter state are due to reduced daily food intake and increased whole-body daily energy expenditure (Warner et al. 2010). We recently reported that plasma levels of FGF21, along with its local FGF21 protein content in liver and brown adipose tissue, increase in the Siberian hamster when transitioning from its long day fat state to that of its short day lean state, suggesting that FGF21 may play a role in facilitating the shift in metabolic phenotype (Samms et al. 2014). In support of this, our studies demonstrated that treatment of the Siberian hamster with recombinant FGF21 reduced body weight due to an increase in whole-body energy expenditure, which was associated with a switch in metabolic fuel utilisation from carbohydrate to fat oxidation (Murphy et al. 2013).

In addition to its whole body effects, FGF21 has also been shown to have distinct local effects in the liver. Both whole-body and liver-specific deletion of FGF21 in mice leads to increased hepatic triglyceride (TG) content (Markan et al. 2014). Conversely, exogenously administered FGF21 was reported to lower hepatic fat content and improve hepatic insulin sensitivity when administered to animal models suffering with fatty liver disease (Berglund et al. 2009, Camporez et al. 2013). At the molecular level these effects appear to be associated with the upregulation of transcriptional regulators of hepatic fatty acid oxidation and downregulation of regulators of hepatic fatty acid synthesis (Coskun et al. 2008, Adams et al. 2012). Although these data provide some molecular insight, the exact mechanisms by which FGF21 induces its effects on hepatic metabolism (and in particular its effects on carbohydrate metabolism) and consequently how this then results in protection from increased hepatic lipid content in not well understood. Liver is one of the primary targets of FGF21 under both physiological (Badman et al. 2007, Adams et al. 2010) and pharmacological conditions (Berglund et al. 2009, Fisher et al. 2011) and, as indicated by our recent findings, appears to be a primary source of systemic endogenous FGF21 availability under physiological conditions (Samms et al. 2014). Liver plays a crucial role in the regulation of energy metabolism and insulin action. Disruption of normal hepatic metabolism is associated with excess accumulation of tissue lipid content and is linked to insulin resistance and the metabolic syndrome (Birkenfeld \& Shulman 2014). Therefore, FGF21 may be an attractive target for protection from increased hepatic lipid content and insulin resistance that frequently accompany obesity and diabetes. Thus, the aim of the present study was to investigate the biochemical and molecular pathways responsible for the FGF21-mediated decrease in hepatic TG content, focusing on regulation of the integration of hepatic carbohydrate and fatty acid metabolism. We used Siberian hamsters maintained in their long day high-body-weight state since our recent studies have reported that the metabolic effects of recombinant FGF21 are far more efficacious in this species when maintained in its fat state compared to its lean state (Murphy et al. 2013). The chronic infusion paradigm was designed to mimic the natural increase in circulating, hepatic and brown adipose tissue FGF21 that occurs when animals are exposed to SD (Samms et al. 2014). The data from this study further emphasise the potential of FGF21 as therapeutic for the treatment of obesity and diabetes.

\section{Materials and methods}

\section{Animal housing}

Adult male animals were obtained from a colony of Siberian hamsters (Phodopus sungorus) maintained at the University of Nottingham Biomedical Services Unit (Ebling 1994). All studies were carried out in accordance with the UK Animals (Scientific Procedures) Act of 1986 (project licence: PPL 40/3604) and approved by the University of Nottingham Animal Welfare and Ethical Review Board. Hamsters were group-housed at $\sim 21^{\circ} \mathrm{C}$ and

Published by Bioscientifica Ltd. 
$40 \%$ humidity, and were allowed ad libitum access to water and standard laboratory chow comprising of $19 \%$ protein, 45\% carbohydrate, 9\% fat (Teklad 2019, Harlan, UK). Animals were housed from birth in long-day conditions (LD) of $16 \mathrm{~h}$ light: $8 \mathrm{~h}$ darkness cycle with lights off at 1100.

\section{Experimental design}

The effects of continuously infused recombinant human FGF21 protein (Kharitonenkov et al. 2005) were evaluated in aged-matched ( $\sim 6$ months) adult male Siberian hamsters that had been housed in LD since birth $(n=12)$. Sample size was determined by power calculation on the basis of our previous experiments using the reduction in body weight as the primary experimental end-point. Body weight and food intake were recorded on a weekly basis prior to the start of the experimental period. Animals were then randomly assigned (based on initial body mass using an online randomization plan generator software) to one of two treatment groups (with no blinding performed) in which Alzet osmotic mini-pumps (model 2002, Charles River) were subcutaneously implanted and set to release vehicle (saline; $n=6$ ) or FGF21 ( $1 \mathrm{mg} / \mathrm{kg}$ per day; $n=6)$ for 14 days. The osmotic mini-pumps were inserted below the skin on the flank of the hamster under isoflurane anaesthesia. Hamsters were treated with an analgesic $(5 \mathrm{mg} / \mathrm{kg}$ s.c., Rimadyl, Pfizer Animal Health, Kent, UK), and the wound closed with Michel clips. Post-surgery, hamsters were treated daily for 3 days with an analgesic at $5 \mathrm{mg} / \mathrm{kg}$ body weight (Rimadyl, as above) and additional fluids consisting of $500 \mu \mathrm{l} /$ day $0.9 \%$ sterile saline (Baxter Heathcare, Thetford, UK), in accordance with Laboratory Animal Science Association (LASA) guidelines. Body weight and food intake were recorded on a daily basis. Seven days after surgery animals were transferred to metabolic cages (CLAMS) for a 48-h period with the first $24 \mathrm{~h}$ used as a habituation period and the final $24 \mathrm{~h}$ for the measurement of the metabolic parameters described in the section below. Fourteen days after the start of the experimental period hamsters were euthanized by i.p. injection of sodium pentobarbitone (Euthatal: Rhone Merieux, Harlow, UK) and liver tissues were collected, immediately frozen in liquid nitrogen and subsequently stored at $-80^{\circ} \mathrm{C}$ until the biochemical and molecular analyses described below were conducted.

\section{Whole-body metabolic analysis}

Oxygen consumption $\left(\mathrm{VO}_{2}\right)$ and carbon dioxide production $\left(\mathrm{VCO}_{2}\right)$ were measured concurrently using a modified open-circuit calorimeter known as the CLAMS, as described previously (Warner et al. 2010). $\mathrm{VO}_{2}$ and $\mathrm{VCO}_{2}$ were then used to calculate energy expenditure, respiratory exchange ratio (RER) and the rate of whole-body carbohydrate (COX) and fat (FOX) oxidation, as previously described (Frayn 1983). Measurements were taken at 9-min intervals for $24 \mathrm{~h}$, commencing 7 days after the start of FGF21 treatment. Hamsters had ad libitum access to water and ground chow when in the CLAMS. All measurements were made at room temperature, which was maintained at $\sim 21^{\circ} \mathrm{C}$.

\section{Liver metabolites}

Two hundred to $250 \mathrm{mg}$ of frozen 'wet' liver tissue was freeze-dried and powdered. One part of the freeze-dried tissue $(20-30 \mathrm{mg})$ was used for the determination of acetylcarnitine and long-chain acylcarnitine content using radioenzymatic methods previously described (Cederblad et al. 1990). An aliquot of the freeze-dried liver tissue ( $\sim 20-30 \mathrm{mg}$ ) was also used for the quantitative determination of TG content. Briefly, the tissue total lipid content was extracted using the method by Folch et al. (1957), followed by removal of phospholipids by adding $250 \mathrm{mg}$ of silicic acid, and saponification of TGs to glycerol and free fatty acids (FFAs) using a mixture of $\mathrm{KOH}$ and ethanol (5:95). Samples were then centrifuged and the resulting supernatants used for the enzymatic determination of glycerol. Approximately $10-15 \mathrm{mg}$ of the 'wet' liver was also used to determine hepatic dehydrogenase complex activity expressed as the rate of acetyl-CoA formation (mmol min (kg wet liver tissue)) using methodology described previously by Cederblad et al. (1990).

\section{RNA extraction}

Total RNA was extracted from 30-50 mg of frozen 'wet' liver tissue using TRIzol reagent (Invitrogen). Aliquots of RNA were assessed for purity and quantification was verified using a Nanodrop ND-100 (Thermo Fisher Scientific, Wilmington, DE, USA). Reverse transcription was then carried out from $500 \mathrm{ng}$ of total RNA using the SuperScript III cDNA kit (Invitrogen).

\section{Real-time quantitative PCR}

Taqman primers and probes sets were obtained from Applied Biosystems. Real-time PCR was performed using PCR Universal Master Mix (Applied Biosystems) in a Micro-Amp 96-well plate using an ABI Prism 7000

Published by Bioscientifica Ltd. 
Sequence Detection System (Applied Biosystems). Assays were performed in triplicate. The threshold $(C t)$ values for each triplicate were averaged and the quantification of expression of each gene relative to $\beta$-actin determined using the standard curve method (Tsintzas et al. 2006).

\section{Protein extraction}

Protein was extracted from the organic phase of the RNA extraction homogenate solution. Briefly, $1.5 \mathrm{ml}$ of isopropanol per ml of TRIzol originally used was added to each sample. Samples were mixed and left at room temperature for $10 \mathrm{~min}$ to allow for protein precipitation. Samples were centrifuged at $12000 \mathrm{~g}$ for $10 \mathrm{~min}, 2 \mathrm{ml}$ of wash solution was added and samples were mixed on a daisy wheel for $20 \mathrm{~min}$ at room temperature. Samples were centrifuged at $7500 \mathrm{~g}$ for $5 \mathrm{~min}$ at $4{ }^{\circ} \mathrm{C}$, then pellets were vortexed in $2 \mathrm{ml}$ of $100 \% \mathrm{EtOH}$ and left to stand at room temperature for $20 \mathrm{~min}$. Samples were then centrifuged at $7500 \boldsymbol{g}$ for $5 \mathrm{~min}$ at $4{ }^{\circ} \mathrm{C}$. Protein pellets were then re-dissolved in $400 \mu \mathrm{l}$, of protein re-suspension solution $(50 \mathrm{mM}$ Tris, $4 \%$ SDS and $9 \mathrm{M}$ Urea) and stored at $-80^{\circ} \mathrm{C}$. Quantification of protein concentration in the supernatant from liver tissue was conducted using the Pierce BSA Protein Assay.

\section{Western blotting}

Protein separation was carried out using SDS-PAGE, using 5-20\% gradient gels and then transferred overnight onto a hydrophobic PVDF membrane (GE Healthcare, Little Chalfont, Buckinghamshire, UK). Membranes were then incubated in blocking buffer (e.g., BSA or milk) on a shaker for $1 \mathrm{~h}$. Primary antibodies for target proteins PDK4 (Santa Cruz Biotechnology, Dallas, TX, \#sc-14495), pACC (Cell Signalling, Danvers, MA, USA, \#3661), PGC1 $\alpha$ (Calbiochem, Billerica, MA, USA, \#516557), PPAR $\alpha$ (Abcam, Cambridge, UK, \#8934), sirtuin-1 (SIRT1) (Cell Signalling, \#2310) and housekeeping protein cyclophilin-B (Abcam, \#74173) were diluted in Tris-buffered saline (TBS) and blocking buffer (1-5\%) applied to membranes that were then incubated overnight at $4{ }^{\circ} \mathrm{C}$ on a shaker. Following the incubation period, membranes were incubated with rabbit anti-goat, goat anti-mouse and swine anti-rabbit HRP (Dako, Glostrup, Denmark) secondary antibodies as appropriate at ratio of 1:2000 diluted in TBS-T containing 1-2\% blocking buffer, for $1 \mathrm{~h}$ at room temperature. All immunoreactive proteins were visualized using ECL plus (Amersham Biosciences) and quantified by densitometry using the Quantity One 1D Analysis Software version 4.5 (Bio-Rad Laboratories).

\section{Radiotelemetry}

An additional study was carried out with $\sim 4$ month-oldadult male Siberian hamsters that had been housed in LD since birth $(n=12)$. Core body temperature and activity were measured using radiotelemetry devices (TA10TA-F20) and receivers (RPC1) and ARTv2.1 Software (all Data Sciences International, St Paul, MN, USA). Each hamster was implanted with a telemetry device under general anaesthesia as previously reported (Murphy et al. 2012). After a 7-day recovery period, recordings were made for a period of 7 days to establish baseline parameters. Hamsters were then implanted under general anaesthesia with mini-osmotic pumps as described above for the main study. These delivered vehicle $(n=6)$ or FGF21 $(n=6)$ at a dose of $3 \mathrm{mg} / \mathrm{kg}$ per day. Body weight was recorded daily, and telemetry recordings were made on days 3-4 and days 5-6 after the start of treatment.

\section{Statistical analysis}

Descriptive statistics (mean \pm s.E.м.) were generated using Graphpad Prism (Prism 6.0, GraphPad, San Diego, CA, USA). After checking for normality of distribution and equality of variance, body weight, food intake, telemetry data and CLAMS data were analysed using a two-way (treatment $\times$ sampling time) repeated measures ANOVA with Bonferroni correction used as a post-hoc test. Tissue weights, metabolite analysis, PDC activity, gene expression analysis and protein abundance were analysed using one-way ANOVA or student unpaired $t$-test where appropriate. No animals were excluded from the analysis. Statistical significance was declared at $P<0.05$.

\section{Results}

\section{Body weight, food intake and tissue weights}

In animals chronically treated with FGF21 there was a progressive decrease in body weight during the first 6 days of the infusion period, after which body weight became relatively stable (Fig. 1A). At the end of the 14-day treatment period body weight was decreased by $10 \%$ $(P<0.05)$ in animals treated with FGF21 when compared to vehicle-treated controls at the end of the 14-day treatment period (Fig. 1A). There were no significant effects of chronic FGF21 administration on daily food intake (Fig. 1B). There were 24 and 10\% decreases in the

Published by Bioscientifica Ltd. 

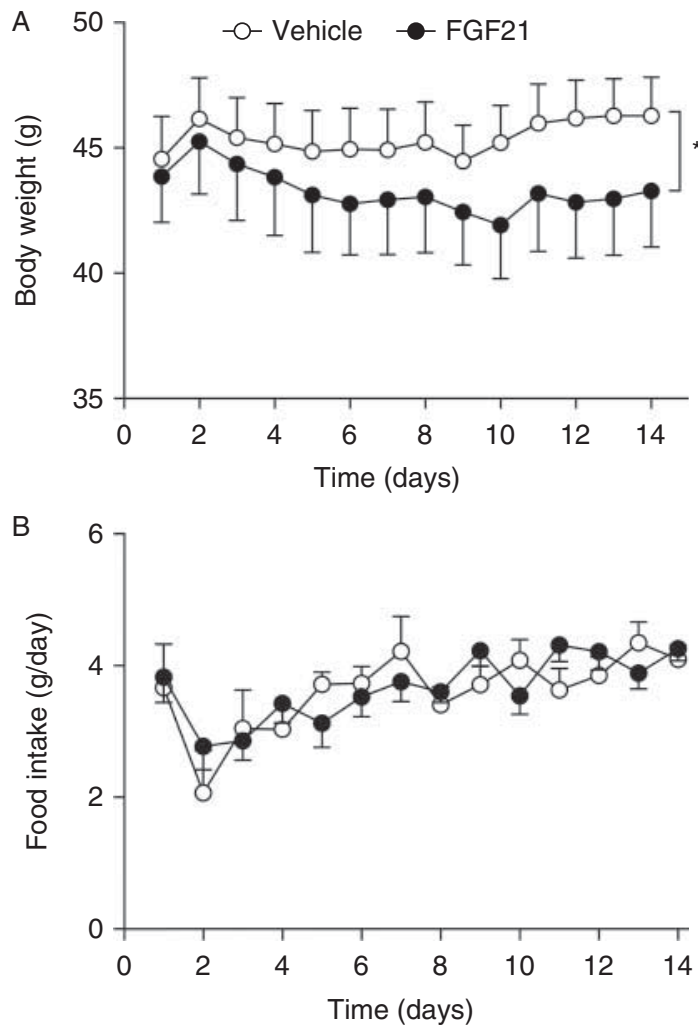

Figure 1

The effect of vehicle $(n=6)$ and FGF21 ( $1 \mathrm{mg} / \mathrm{kg}$ per day; $n=6)$ on (A) body weight ( $\mathrm{g} /$ day) and (B) food intake ( $\mathrm{g} / \mathrm{day}$ ) throughout the 14-day treatment period. Values are group means \pm s.E.M. ${ }^{*} P<0.05$ vs vehicle.

weight of the epididymal white adipose tissue $(P<0.01)$ and liver $(P<0.05)$ weights respectively following 14 days of the FGF21 infusion when compared to those of vehicletreated controls.

\section{Whole-body energy expenditure and carbohydrate and fat oxidation rates}

There was clear circadian variation in metabolic fuel oxidation in animals treated with vehicle, with COX increasing in the dark phase when animals tend to be more active and eat more, and FOX being lowest in the light phase when animals tend to be less active and food intake is reduced (Fig. 2C and D). There was a significant $(P<0.05)$ increase in daily energy expenditure in animals chronically treated with FGF21 when compared to that of vehicle (Fig. 2A). Similarly, FGF21 infusion resulted in significantly lower $(P<0.01)$ RER values when compared to that of vehicle (Fig. 2B). As a result, there were clear effects of FGF21 administration on carbohydrate and fatty acid oxidation by day 8 of the infusion period. Specifically, there was a significant reduction
(9\%, $P<0.001)$ in carbohydrate oxidation (Fig. 2C) with a reciprocal increase $(58 \%, P<0.001)$ in fatty acid oxidation (Fig. 2D).

\section{Hepatic metabolism}

Following the 14-day infusion period, there was approximately a $40 \%$ decrease $(P<0.05)$ in hepatic PDC activity in animals treated with FGF21 when compared to that of vehicle-treated controls (Fig. 3A). In line with the decrease in PDC activity, there was approximately a $34 \%(P<0.05)$ decrease in hepatic acetylcarnitine accumulation, an index of PDC flux, in animals treated with FGF21 when compared to that of vehicle-treated controls (Fig. 3B). There was also a significant reduction $(P<0.05)$ in hepatic TG content, which was decreased on average by $\sim 47 \%$ in animals treated with FGF21 when compared to vehicletreated controls following 14 days of the treatment period (Fig. 4A). Furthermore, in line with the decreased hepatic TG content, there was a $35 \%(P<0.05)$ increase in hepatic long-chain acylcarnitine accumulation in animals treated with FGF21 when compared to that of vehicle-treated control animals (Fig. 4B).

\section{Hepatic mRNA and protein expression}

In order to identify the potential molecular mechanisms by which FGF21 may be regulating hepatic lipid and carbohydrate metabolism, mRNA and protein analysis was conducted. Following 14 days of the infusion period, there were clear FGF21-induced effects on hepatic mRNA and protein expression of several known regulators of carbohydrate and fatty acid metabolism. FGF21 treatment resulted in a 1.8-fold increase in PDK4 $(P<0.05$, Fig. $3 \mathrm{C})$, twofold increase in pACC $(P<0.05$, Fig. $4 \mathrm{C})$ and 1.6-fold increase in SIRT1 (Fig. 5) protein abundance when compared to vehicle-treated animals. In animals treated with FGF21 there was a trend towards increased mRNA expression of the known transcriptional regulators of carbohydrate and fat metabolism $\operatorname{PPAR} \alpha(P=0.08$, Fig. 6A) and PGC1 $\alpha(P=0.10$, Fig. 6C). In line with these effects there was a 1.8 -fold $(P<0.05)$ increase in hepatic protein abundance of PGC1 $\alpha$ in animals treated with FGF21 when compared to vehicle (Fig. 6B), but there was no significant effect on PPAR $\alpha$ protein content (Fig. 6D).

\section{Body temperature and locomotor activity}

In order to identify whether weight loss might be a reflection of increased thermogenesis or increased physical

Published by Bioscientifica Ltd. 


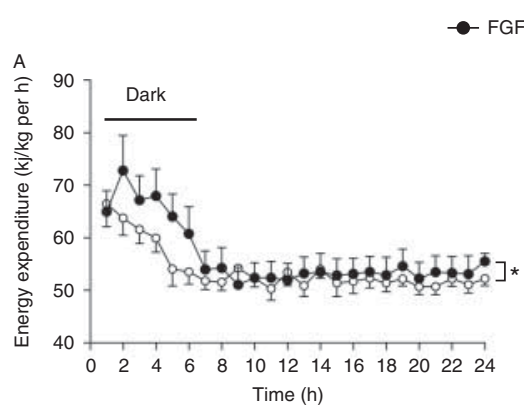

FGF21 - - Vehicle

B
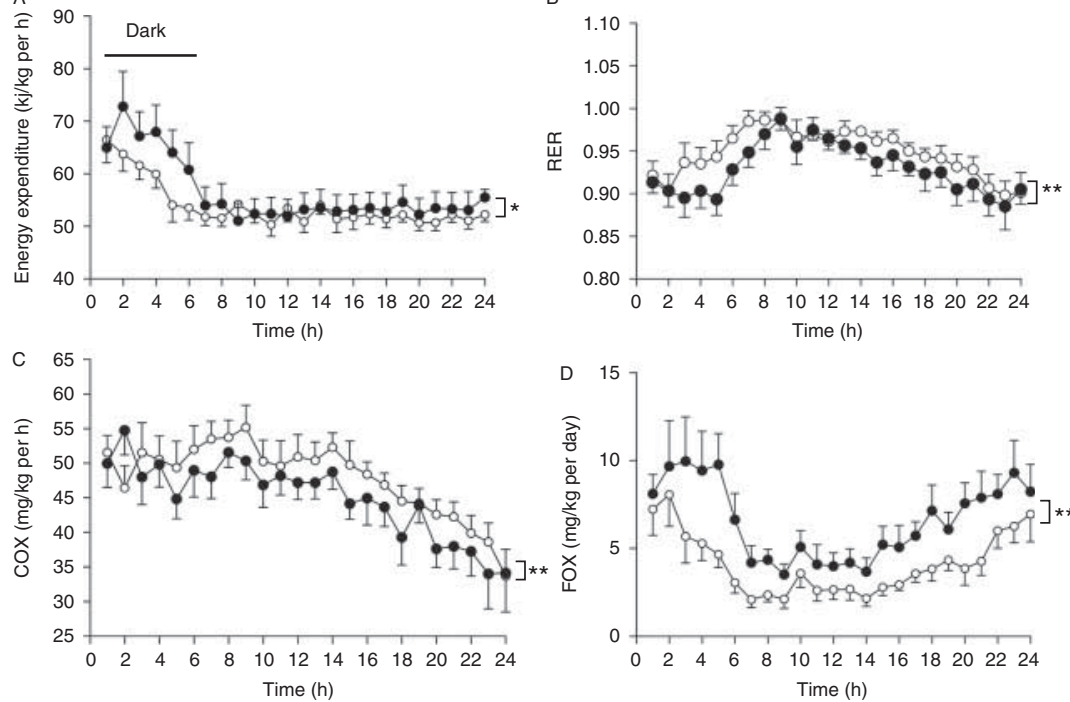

Figure 2

The effect of vehicle $(n=6)$ and FGF21 ( $1 \mathrm{mg} / \mathrm{kg}$ per day; $n=6)$ on (A) whole-body energy expenditure ( $\mathrm{kj} / \mathrm{kg}$ per $\mathrm{h}),(B)$ respiratory exchange ratio (RER), (C) carbohydrate (COX, mg/kg per h) and (D) fat oxidation

(FOX, mg/kg per $\mathrm{h}$ ) rates for a 24-h period following 7 days of FGF21 treatment. Values are group means \pm s.E.M. ${ }^{*} P<0.05$ and $* * P<0.01$ treatment effect vs vehicle.

activity, core body temperature and locomotor activity were monitored by radiotelemetry in a separate group of hamsters that were being infused with $3 \mathrm{mg} / \mathrm{kg}$ per day FGF21. This treatment induced significant weight loss as compared to the vehicle-infused control group (Fig. 7 top, treatment $\times$ time interaction $F=16.2, P<0.0001$ ). Core body temperature showed clear nocturnal-diurnal variation in both vehicle- and FGF21-treated hamsters (Fig. 7 middle), but there were no significant effects of FGF21 treatment on mean, maximum, or minimum body temperature at either 3-4 days or 5-6 days after the start of treatment. Likewise, both vehicle- and FGF21-treated hamsters displayed clear daily variation in their activity patterns (Fig. 7 bottom), but despite some evidence of increased variation in activity levels between individuals in the FGF21-treated group, there was no significant effect on any parameter of locomotor activity.

\section{Discussion}

The primary objective of this study was to investigate the mechanisms by which FGF21 affects hepatic integration of carbohydrate and fat metabolism in a seasonal animal model of adiposity. Chronic treatment with human recombinant FGF21 led to reduced body weight and fat mass, increased whole-body energy expenditure, and a clear shift in metabolic fuel utilization, with a preferential

increase in FOX and decrease in COX. These observations are consistent with previous studies of the effects of FGF21 in other dietary and genetic rodent models of obesity (Coskun et al. 2008, Hale et al. 2012) and by using a lower dose of FGF21 than in our previous study (Murphy et al. 2013) we were able to observe effects of FGF21 on metabolic physiology that are independent of the suppressive effects of FGF21 on food intake in hamsters. The Siberian hamsters are a natural model of adiposity that, when fed a high-fat diet, do not increase their caloric intake and so do not gain additional weight. Even in longterm high-fat diet studies where some increase in food intake can be observed in Siberian hamsters, this does not result in weight gain, rather the animals increase thermogenesis via increased sympathetic nervous system (SNS) activation of brown fat (McElroy et al. 1986). Although hamsters have a different biology from mice and rats, which is a reflection of their evolution and ecology, they cannot be considered to be any less valid as a model for understanding fundamental mechanisms of action of hormones than other rodents; indeed, using a variety of animal models has overall translational benefits (Ebling 2014).

These effects of FGF21 on energy expenditure are unlikely to be secondary to effects on locomotor activity or thermogenesis, as in a second study using radiotelemetry we found no evidence for either increased locomotor

Published by Bioscientifica Ltd. 


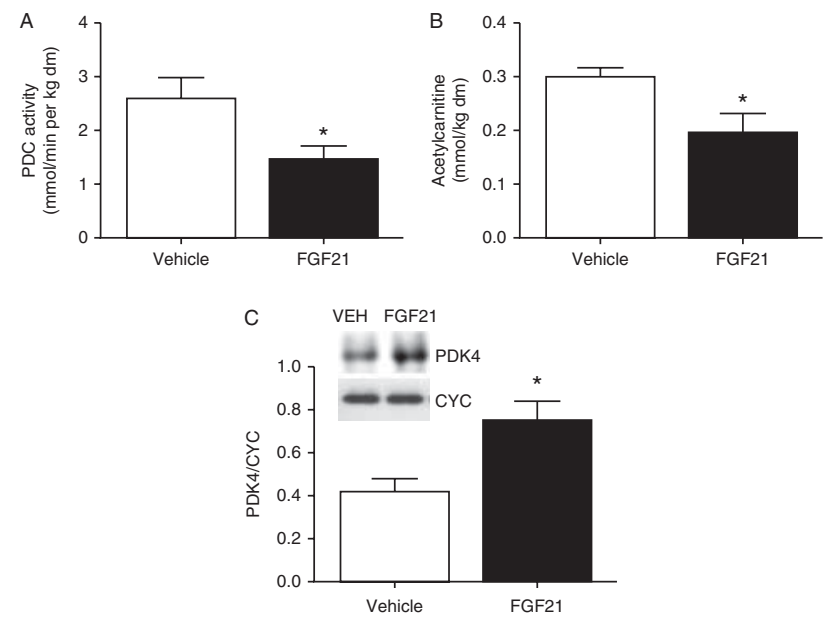

Figure 3

The effect of vehicle ( $n=6)$ and FGF21 ( $1 \mathrm{mg} / \mathrm{kg}$ per day; $n=6)$ on (A) pyruvate dehydrogenase complex activity (PDC, $\mathrm{mmol} / \mathrm{min}$ per $\mathrm{kg} \mathrm{dm}$ ), (B) acetylcarnitine $(\mathrm{mmol} / \mathrm{kg} \mathrm{dm})$ and (C) pyruvate dehydrogenase 4 (PDK4) at the end of the 14-day treatment period. Values are group means \pm s.E.M. ${ }^{*} P<0.05$ vs vehicle.

activity or increased body temperature. Again such observations are consistent with studies in mice and rats where treatment with FGF21 did not affect activity (Coskun et al. 2008, Sarruf et al. 2010), or where genetic modification of mice to produce overexpression of FGF21 in the liver actually decreased nocturnal body temperature (Inagaki et al. 2007) and activity (Bookout et al. 2013).

At the tissue level, we have shown for the first time that these whole-body metabolic effects are associated with reduced hepatic PDC activity, reduced acetylcarnitine accumulation and increased long-chain acylcarnitine content, which collectively indicate a FGF21-induced decrease in hepatic COX with a concomitant increase in FOX. This hepatic shift in metabolic fuel utilisation from carbohydrate (CHO) towards fat oxidation was underpinned by i) a PDK4-induced impairment in PDC activation through upregulation of its transcriptional activator PGC1 $\alpha$; and ii) inhibition of ACC, as indicated by increased phosphorylation (deactivation) of the protein. This deactivation can potentially alleviate the ACC-mediated inhibition of carnitine palmitoyl transferase 1 (CPT1), resulting in increased delivery of cytosolic long-chain fatty acids (presumably originating from either adipose tissue and/or the hepatic TG content that decreased by 24 and $47 \%$ respectively in response to treatment with FGF21) across the mitochondrial membrane for subsequent $\beta$-oxidation, as indicated by an increase in hepatic long-chain acylcarnitine content.
The PDC regulates the entry of pyruvate into the TCA cycle for subsequent ATP production, linking the glycolytic degradation of glucose to the TCA cycle through the irreversible decarboxylation of pyruvate into acetyl-CoA (Sugden \& Holness 2003). Here, in accordance with the whole-body decrease in COX, there was a $40 \%$ decrease in hepatic PDC activity, with a concomitant $65 \%$ decrease in acetylcarnitine accumulation, which may be indicative of decreased hepatic PDC flux (Tsintzas et al. 2007, Wall et al. 2011). Importantly, the PDC is subject to both acute and chronic inhibition via PDK4, which phosphorylates and inhibits its activity (Sugden et al. 2009). We have previously shown that selective upregulation of PDK4 and a concomitant inactivation of PDC in human skeletal muscle is linked to a decrease in insulin-stimulated glucose turnover and oxidation in metabolic states characterized by elevated lipid availability and insulin resistance (Chokkalingam et al. 2007, Tsintzas et al. 2007). In the present study, in line with the decreased hepatic PDC activity, we report a significant increase in protein abundance of PDK4 in animals treated with FGF21 when compared to vehicle. Since PDC is the rate-limiting step in glucose oxidation, taken together these data indicate that the FGF21-induced suppression of hepatic carbohydrate oxidation may occur via PDK4-mediated suppression of PDC activity. Thus, for the first time here we provide a potential mechanistic explanation for the FGF21mediated inhibition of hepatic carbohydrate oxidation. We have previously shown in human skeletal muscle that

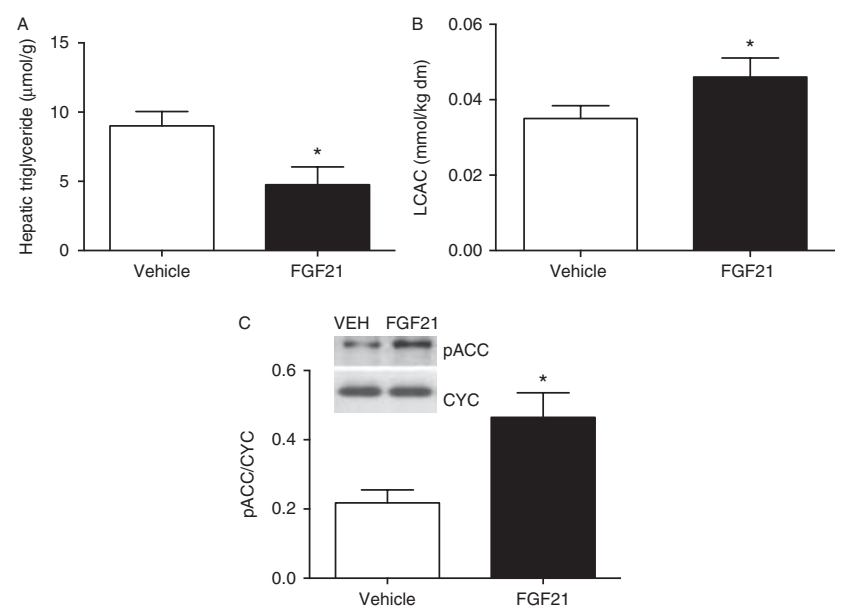

Figure 4

The effect of vehicle $(n=6)$ and FGF21 ( $1 \mathrm{mg} / \mathrm{kg}$ per day; $n=6)$ on (A) hepatic triglyceride content $(\mu \mathrm{mol} / \mathrm{g}),(B)$ long chain acylcarnitine (LCAC, $\mathrm{mmol} / \mathrm{kg} \mathrm{dm}$ ) accumulation and (C) phosphorylated acetyl-CoA carboxylase (pACC) at the end of the 14-day treatment period. Values are group means \pm s.E.M. ${ }^{*} P<0.05$ vs vehicle.

Published by Bioscientifica Ltd 


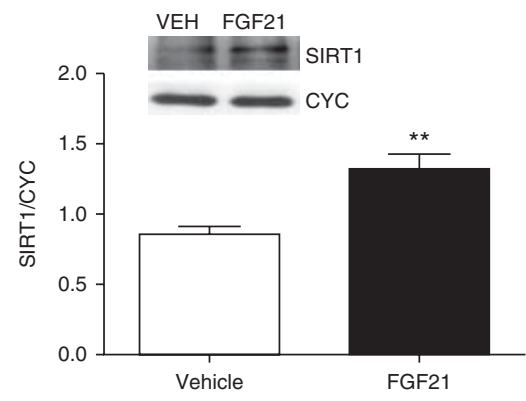

Figure 5

The effects of vehicle (saline; $n=6)$ and FGF21 ( $1 \mathrm{mg} / \mathrm{kg}$ per day; $n=6)$ on SIRT 1 protein abundance normalised to cyclophilin-B (CYC) after 14 days of infusion. Values are means \pm s.E.M. $* * P<0.01$ vs vehicle.

the accumulation of tissue lipids in response to increased fat oxidation plays an important role in the induction of PDK4 and impairment of PDC activity (Tsintzas et al. 2007), and therefore it is possible that in the present study the accumulation of intrahepatic lipid metabolites (as indicated by an increase in long-chain acylcarnitine content) may be responsible for the upregulation of PDK4 protein content. It is also possible that this FGF21-induced hepatic downregulation of carbohydrate oxidation may be required to facilitate the shift in hepatic fuel utilisation towards fat oxidation and subsequent decrease in hepatic TG content. In support of the latter notion, unpublished data from our laboratory indicates that the FGF21-induced impairment in hepatic PDC activity (mins) occurs before the accumulation of hepatic long-chain acylcarnitine content and inhibition of ACC (h).

To further investigate the molecular mechanism that may be responsible for the FGF21-induced increase in PDK4 protein abundance, known downstream targets of FGF21 (PGC1 $\alpha$ and SIRT1) and reported activators of PDK4 expression were measured (Wende et al. 2005). At the end of the infusion period there was a significant increase in protein abundance of the key hepatic transcriptional co-regulators of energy metabolism PGC1 $\alpha$ and SIRT1 in animals treated with FGF21 when compared to control. In the liver, FGF21 has been reported to be capable of directly inducing PGC1 $\alpha$ mRNA expression and protein abundance (Coskun et al. 2008, Adams et al. 2012). Potthoff et al. have also shown using hepatic-specific PGC1 KO mice that this protein is critical to the ability of FGF21 to increase hepatic $\beta$-oxidation, ketogenesis and TCA cycle flux (Potthoff et al. 2009). Furthermore, PGC1 $\alpha$ has been shown to be capable of directly inducing PDK4 expression in skeletal muscle and hepatocytes (Wende et al. 2005, Attia et al. 2010). Collectively, these data suggest that the FGF21-mediated induction of PDK4 may occur via a PGC1 $\alpha$ dependent mechanism; however, further investigation is required to confirm this and elucidate the upstream signalling cascade responsible for this effect.

Hepatic fatty acid metabolism is also subject to acute and chronic regulation via the master enzymatic switch acetyl-CoA carboxylase (ACC), which catalyses the conversion of acetyl-CoA to malonyl-CoA, the essential substrate in fatty acid synthesis but also an allosteric inhibitor of CPT1 (McGarry \& Brown 1997). Importantly, ACC is itself subject to inhibition by phosphorylation, thereby lowering the production of malonyl-CoA and alleviating its inhibitory effect on CPT1 subsequently increasing mitochondrial fatty acid oxidation (Foster 2012). In the present investigation, there was a significant increase in the phosphorylated (and therefore inhibited) form of ACC in the liver of animals treated with FGF21. Thus, it appears that chronic FGF21 administration may be associated with stable inactivation of hepatic ACC therefore lowering tissue levels of malonylCoA and alleviating its inhibitory effect on CPT1, allowing the transport of long-chain fatty acids into the mitochondria for their subsequent $\beta$-oxidation. Although CPT1 activity or expression was not measured in the
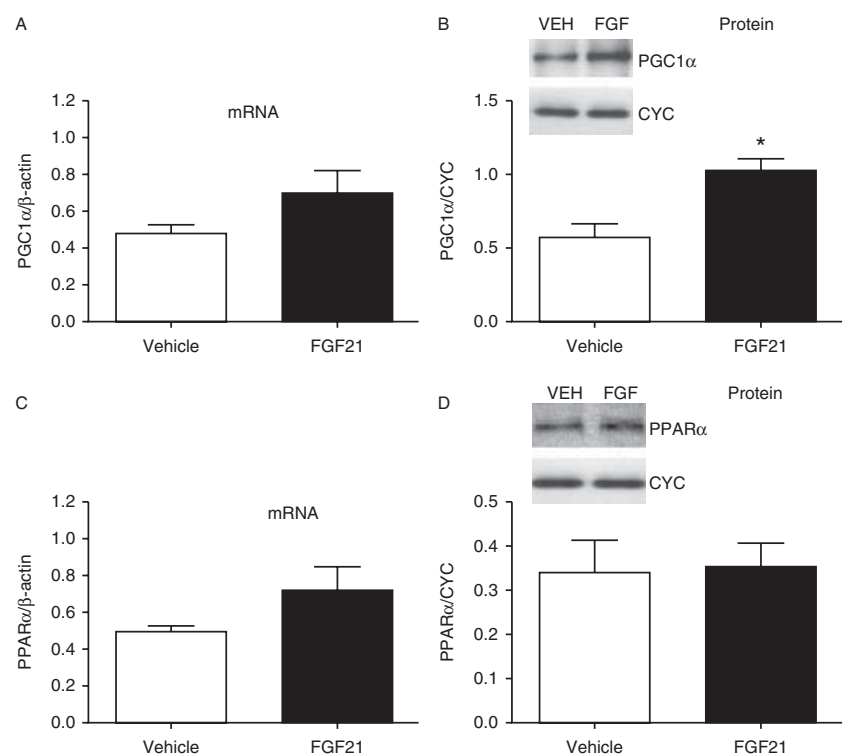

\section{Figure 6}

The effects of vehicle (saline; $n=6$ ) and FGF21 ( $1 \mathrm{mg} / \mathrm{kg}$ per day; $n=6)$ on ( $A$ and $B$ ) peroxisome proliferator-activated receptor gamma co-activator 1 alpha (PGC1 $\alpha$ ), and ( $C$ and $D)$ peroxisome proliferator-activated receptor alpha (PPAR $\alpha$ ) mRNA gene expression normalised to $\beta$-actin and protein abundance normalised to cyclophilin-B (CYC) after 14-days of infusion. Values are means \pm s.E.M. ${ }^{*} P<0.05$ vs vehicle.

Published by Bioscientifica Ltd 


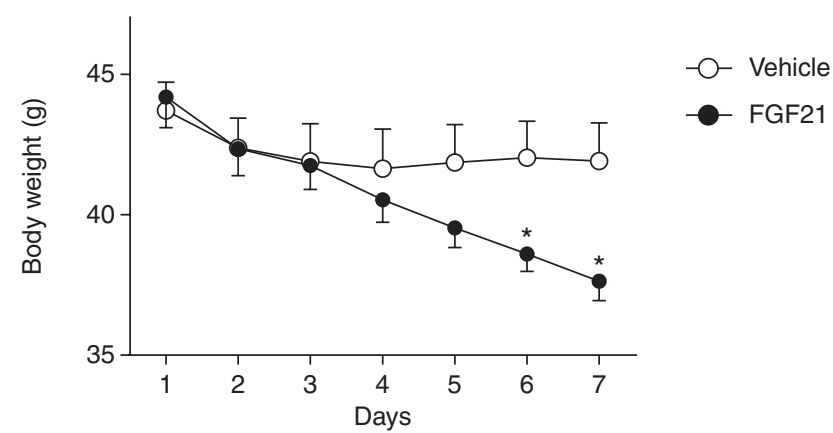

induced obesity in mice was associated with a substantial reduction in several genes associated with hepatic fatty acid synthesis including ACC. Interestingly, FGF21 has been shown to be capable of directly activating AMPK activity and phosphorylating (inhibiting) its downstream target ACC in adipose tissue of mice (Chau et al. 2010). The same authors also showed that FGF21 induced phosphorylation of AMPK activates SIRT1 and PGC1 $\alpha$, which led to the suggestion that activation of the AMPK/PGC1 $\alpha /$ SIRT1 pathway plays a crucial role in
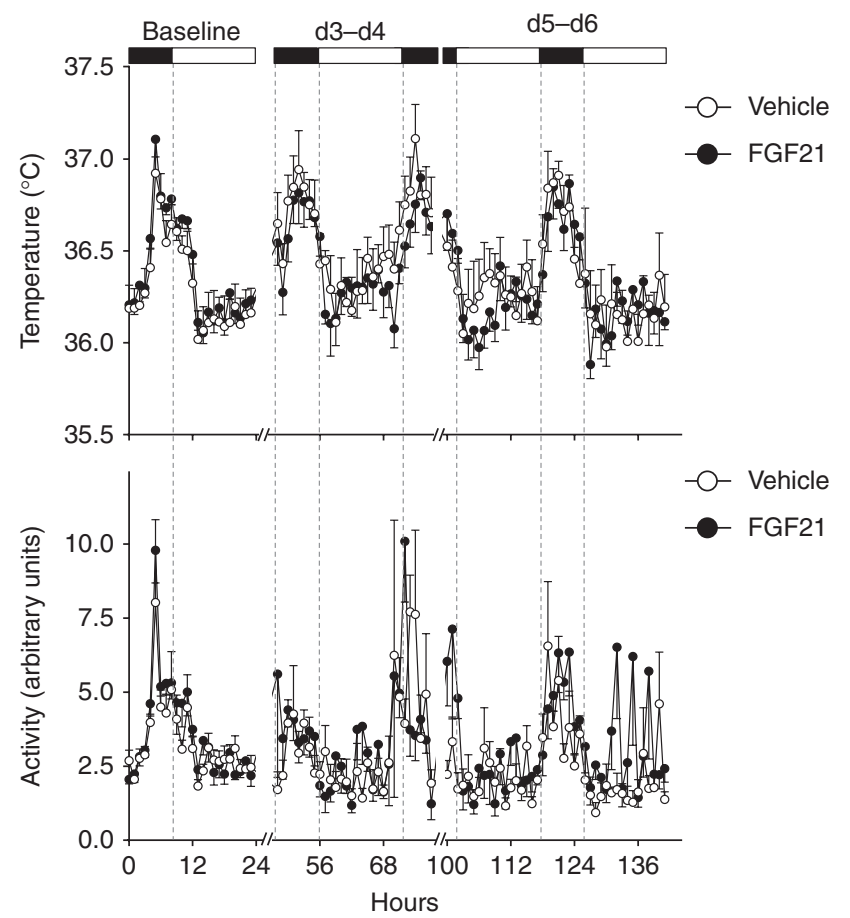
mediating the effects of FGF21 on adipose tissue energy metabolism (Chau et al. 2010). In support of these data here, we report a significant increase in hepatic SIRT1 protein abundance in animals treated with FGF21 when compared to that of vehicle. Thus, it can be argued that the FGF21-mediated inactivation of ACC may be a result of increased SIRT1 protein abundance and therefore

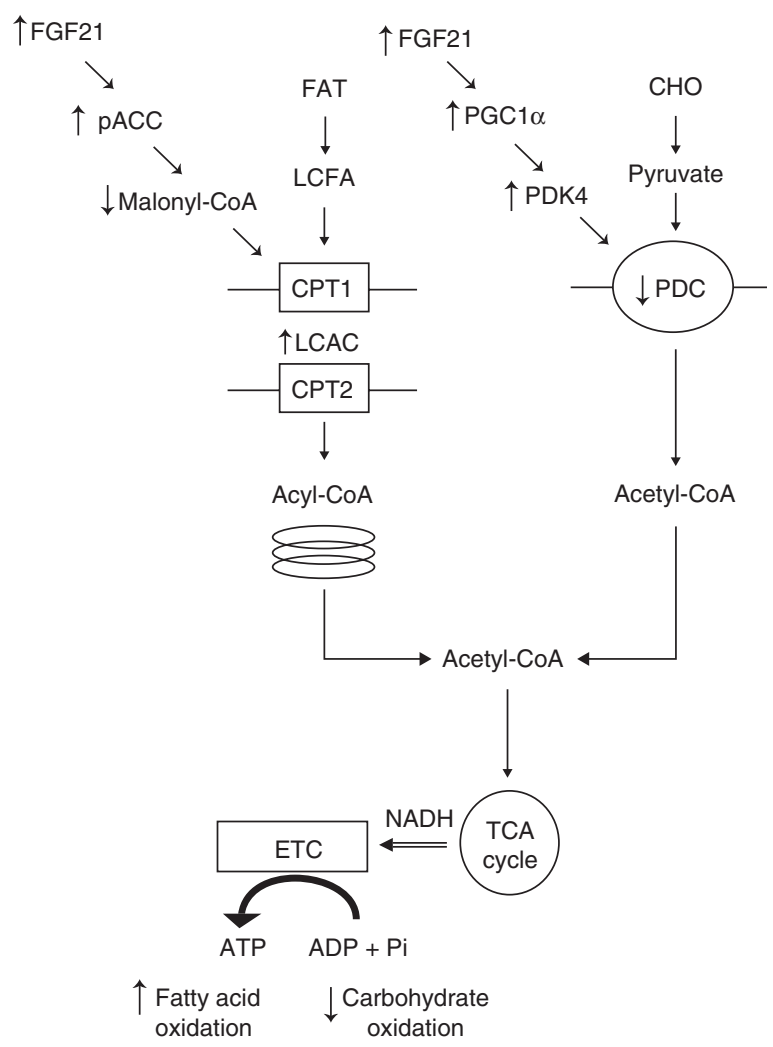

Figure 7

Body weight (top), mean core body temperature (middle) and locomotor activity (bottom) in adult male hamsters infused with vehicle $(O, n=6)$ or recombinant human FGF21 at $3 \mathrm{mg} / \mathrm{kg}$ per day $(O, n=6)$. Values are group mean \pm S.E.M. for the telemetry variables prior to treatment (baseline), and on day 3 and days $5-6$ after the start of treatment, $* P<0.05$ vs vehicle. Solid bars depict the 8-h dark phase.

present study, our data suggest that flux through the CPT1 reaction (an index of entry of fatty acyl CoAs into the mitochondria) was increased, as indicated by an increase in hepatic long-chain acylcarnitine content. Previous studies in mice showed no effect of FGF21 on hepatic Cpt1 mRNA expression (Coskun et al. 2008) and higher CPT1 protein but not mRNA expression in livers of FGF21transgenic mice when compared with wildtype animals (Inagaki et al. 2007), suggesting that the effects of FGF21 on hepatic CPT1 may occur at a post-transcriptional level.

Coskun et al. (2008) have also reported that following 14 days of continuous infusion of FGF21, resistance to diet 
activation (deacetylation) of its downstream targets. However, it is important to note that in addition to the direct effects of FGF21 on hepatic ACC activity, it may also be the case that increased delivery of fatty acids into the mitochondria is facilitated via an indirect mechanism due to lower production of acetyl-CoA through the PDC reaction and therefore lower levels of malonyl-CoA production, as indicated by the reduction in hepatic PDC activity and acetylacarnitine accumulation in response to FGF21 in the present study. A schematic diagram of the proposed mechanism(s) by which FGF21 is regulating hepatic fatty acid and carbohydrate metabolism is shown in Fig. 8.

In summary, the present study provides novel data indicating that the FGF21-induced reduction in hepatic lipid content is associated with a shift in metabolic fuel utilisation from $\mathrm{CHO}$ to fat that is facilitated by i) hepatic PDK4-induced impairment in PDC activation, the ratelimiting step in glucose oxidation and ii) inhibition of ACC, which controls the production of the metabolic inhibitor of CPT1 and hence the delivery of long-chain fatty acids across the mitochondrial membrane for subsequent $\beta$-oxidation. Our data also indicate that the FGF21-induced activation of the PGC1 $\alpha$ and SIRT1 pathway may underpin this dual effect of FGF21 on carbohydrate and fat oxidation in the liver. Thus, the data presented in this study provide novel mechanistic support for the notion that FGF21 exerts profound metabolic benefits in the liver by modulating its nutrient flux through the carbohydrate metabolism pathway that facilitates the shift in fuel utilisation towards fat oxidation, and therefore may be an attractive target for protection from increased hepatic lipid content and insulin resistance that frequently accompany obesity and diabetes.

\section{Declaration of interest}

The authors declare that there is no conflict of interest that could be perceived as prejudicing the impartiality of the research reported.

\section{Funding}

R J Samms was supported by a doctoral training award funded by the Biotechnology and Biological Sciences Research Council (BBSRC) UK; research costs were supported by Eli Lilly, a BBSRC Project Grant (BB/M001555/1) and a BBSRC Strategic Skills Award.

\section{Author contribution statement}

$\mathrm{R} J$ Samms and $\mathrm{K}$ Tsintzas wrote the manuscript and researched data; M Murphy, M J Fowler and S Cooper researched data and reviewed the manuscript; $P$ Emmerson, T Coskun, A C Adams and A Kharitonenkov reviewed and edited the manuscript; $F$ J $P$ Ebling designed studies, researched data and reviewed and edited the manuscript. $P$ Emmerson, T Coskun, A C Adams and A Kharitonenkov are employees of Eli Lilly and Company.

\section{References}

Adams AC, Astapova I, Fisher FM, Badman MK, Kurgansky KE, Flier JS, Hollenberg AN \& Maratos-Flier E 2010 Thyroid hormone regulates hepatic expression of fibroblast growth factor 21 in a PPAR $\alpha$ dependent manner. Journal of Biological Chemistry 285 14078-14082. (doi:10.1074/jbc.C110.107375)

Adams AC, Yang C, Coskun T, Cheng CC, Gimeno RE, Luo Y \& Kharitonenkov A 2012 The breadth of FGF21's metabolic actions are governed by FGFR1 in adipose tissue. Molecular Metabolism 2 31-37. (doi:10.1016/j.molmet.2012.08.007)

Attia RR, Connnaughton S, Boone LR, Wang F, Elam MB, Ness GC, Cook GA \& Park EA 2010 Regulation of pyruvate dehydrogenase kinase 4 (PDK4) by thyroid hormone: role of the peroxisome proliferator-activated receptor gamma coactivator (PGC-1 $\alpha$ ). Journal of Biological Chemistry 285 2375-2385. (doi:10.1074/jbc.M109.039081)

Badman MK, Pissios P, Kennedy AR, Koukos G, Flier JS \& Maratos-Flier E 2007 Hepatic fibroblast growth factor 21 is regulated by $\operatorname{PPAR} \alpha$ and is a key mediator of hepatic lipid metabolism in ketotic states. Cell Metabolism 5 426-437. (doi:10.1016/j.cmet.2007.05.002)

Berglund ED, Li CY, Bina HA, Lynes SE, Michael MD, Shanafelt AB, Kharitonenkov A \& Wasserman DH 2009 Fibroblast growth factor 21 controls glycemia via regulation of hepatic glucose flux and insulin sensitivity. Endocrinology 150 4084-4093. (doi:10.1210/en.2009-0221)

Birkenfeld AL \& Shulman GI 2014 Nonalcoholic fatty liver disease, hepatic insulin resistance, and type 2 diabetes. Hepatology 59 713-723. (doi:10.1002/hep.26672)

Bookout AL, de Groot MH, Owen BM, Lee S, Gautron L, Lawrence HL, Ding X, Elmquist JK, Takahashi JS, Mangelsdorf DJ et al. 2013 FGF21 regulates metabolism and circadian behavior by acting on the nervous system. Nature Medicine 19 1147-1152. (doi:10.1038/nm.3249)

Camporez JP, Jornayvaz FR, Petersen MC, Pesta D, Guigni BA, Serr J, Zhang D, Kahn M, Samuel VT, Jurczak MJ et al. 2013 Cellular mechanisms by which FGF21 improves insulin sensitivity in male mice. Endocrinology 154 3099-3109. (doi:10.1210/en.2013-1191)

Cederblad G, Carlin JI, Constantin-Teodosiu D, Harper P \& Hultman E 1990 Radioisotopic assays of CoASH and carnitine and their acetylated forms in human skeletal muscle. Analytical Biochemistry 185 274-278. (doi:10.1016/0003-2697(90)90292-H)

Chau MD, Gao J, Yang Q, Wu Z \& Gromada J 2010 Fibroblast growth factor 21 regulates energy metabolism by activating the AMPK-SIRT1-PGC- $1 \alpha$ pathway. PNAS 107 12553-12558. (doi:10.1073/pnas.1006962107)

Chokkalingam K, Jewell K, Norton L, Littlewood J, van Loon LJ, Mansell P, Macdonald IA \& Tsintzas K 2007 High-fat/low-carbohydrate diet reduces insulin-stimulated carbohydrate oxidation but stimulates nonoxidative glucose disposal in humans: an important role for skeletal muscle pyruvate dehydrogenase kinase 4 . Journal of Clinical Endocrinology and Metabolism 92 284-292. (doi:10.1210/jc.2006-1592)

Coskun T, Bina HA, Schneider MA, Dunbar JD, Hu CC, Chen Y, Moller DE \& Kharitonenkov A 2008 Fibroblast growth factor 21 corrects obesity in mice. Endocrinology 149 6018-6027. (doi:10.1210/en.2008-0816)

Ebling FJ 1994 Photoperiodic differences during development in the dwarf hamsters Phodopus sungorus and Phodopus campbelli. General and Comparative Endocrinology 95 475-482. (doi:10.1006/gcen.1994.1147)

Ebling FJ 2014 On the value of seasonal mammals for identifying mechanisms underlying the control of food intake and body weight. Hormones and Behavior 66 56-65. (doi:10.1016/j.yhbeh.2014.03.009)

Published by Bioscientifica Ltd. 
Fisher FM, Estall JL, Adams AC, Antonellis PJ, Bina HA, Flier JS, Kharitonenkov A, Spiegelman BM \& Maratos-Flier E 2011 Integrated regulation of hepatic metabolism by fibroblast growth factor 21 (FGF21) in vivo. Endocrinology 152 2996-3004. (doi:10.1210/en. 2011-0281)

Folch J, Lees M \& Sloane Stanley GH 1957 A simple method for the isolation and purification of total lipides from animal tissues. Journal of Biological Chemistry 226 497-509.

Foster DW 2012 Malonyl-CoA: the regulator of fatty acid synthesis and oxidation. Journal of Clinical Investigation 122 1958-1959. (doi:10.1172/ JCI63967)

Frayn KN 1983 Calculation of substrate oxidation rates in vivo from gaseous exchange. Journal of Applied Physiology: Respiratory, Environmental and Exercise Physiology 55 628-634.

Gaich G, Chien JY, Fu H, Glass LC, Deeg MA, Holland WL, Kharitonenkov A, Bumol T, Schilske HK \& Moller DE 2013 The effects of LY2405319, an FGF21 analog, in obese human subjects with type 2 diabetes. Cell Metabolism 18 333-340. (doi:10.1016/j.cmet.2013.08.005)

Gimeno RE \& Moller DE 2014 FGF21-based pharmacotherapy - potential utility for metabolic disorders. Trends in Endocrinology and Metabolism 25 303-311. (doi:10.1016/j.tem.2014.03.001)

Hale C, Chen MM, Stanislaus S, Chinookoswong N, Hager T, Wang M, Veniant MM \& Xu J 2012 Lack of overt FGF21 resistance in two mouse models of obesity and insulin resistance. Endocrinology 153 69-80. (doi:10.1210/en.2010-1262)

Inagaki T, Dutchak P, Zhao G, Ding X, Gautron L, Parameswara V, Li Y, Goetz R, Mohammadi M, Esser V et al. 2007 Endocrine regulation of the fasting response by PPAR $\alpha$-mediated induction of fibroblast growth factor 21. Cell Metabolism 5 415-425. (doi:10.1016/j.cmet.2007.05.003)

Kharitonenkov A \& Adams AC 2014 Inventing new medicines: the FGF21 story. Molecular Metabolism 3 221-229. (doi:10.1016/j.molmet. 2013.12.003)

Kharitonenkov A, Shiyanova TL, Koester A, Ford AM, Micanovic R, Galbreath EJ, Sandusky GE, Hammond LJ, Moyers JS, Owens RA et al. 2005 FGF-21 as a novel metabolic regulator. Journal of Clinical Investigation 115 1627-1635. (doi:10.1172/JCI23606)

Markan KR, Naber MC, Ameka MK, Anderegg MD, Mangelsdorf DJ, Kliewer SA, Mohammadi M \& Potthoff MJ 2014 Circulating FGF21 is liver derived and enhances glucose uptake during refeeding and overfeeding. Diabetes 63 4057-4063. (doi:10.2337/db14-0595)

McElroy JF, Mason PW, Hamilton JM \& Wade GN 1986 Effects of diet and photoperiod on NE turnover and GDP binding in Siberian hamster brown adipose tissue. American Journal of Physiology 250 R383-R388.

McGarry JD \& Brown NF 1997 The mitochondrial carnitine palmitoyltransferase system. From concept to molecular analysis. European Journal of Biochemistry 244 1-14. (doi:10.1111/j.1432-1033. 1997.00001.x)

Murphy M, Jethwa PH, Warner A, Barrett P, Nilaweera KN, Brameld JM \& Ebling FJ 2012 Effects of manipulating hypothalamic triiodothyronine concentrations on seasonal body weight and torpor cycles in Siberian hamsters. Endocrinology 153 101-112. (doi:10.1210/en.2011-1249)
Murphy M, Samms R, Warner A, Bolborea M, Barrett P, Fowler MJ, Brameld JM, Tsintzas K, Kharitonenkov A, Adams AC et al. 2013 Increased responses to the actions of fibroblast growth factor 21 on energy balance and body weight in a seasonal model of adiposity. Journal of Neuroendocrinology 25 180-189. (doi:10.1111/j.1365-2826.2012.02383.x)

Potthoff MJ, Inagaki T, Satapati S, Ding X, He T, Goetz R, Mohammadi M, Finck BN, Mangelsdorf DJ, Kliewer SA et al. 2009 FGF21 induces PGC- $1 \alpha$ and regulates carbohydrate and fatty acid metabolism during the adaptive starvation response. PNAS 106 10853-10858. (doi:10.1073/ pnas.0904187106)

Samms RJ, Fowler MJ, Cooper S, Emmerson P, Coskun T, Adams AC, Kharitonenkov A, Tsintzas K \& Ebling FJ 2014 Photoperiodic regulation of FGF21 production in the Siberian hamster. Hormones and Behavior 66 180-185. (doi:10.1016/j.yhbeh.2014.03.013)

Sarruf DA, Thaler JP, Morton GJ, German J, Fischer JD, Ogimoto K \& Schwartz MW 2010 Fibroblast growth factor 21 action in the brain increases energy expenditure and insulin sensitivity in obese rats. Diabetes 59 1817-1824. (doi:10.2337/db09-1878)

Sugden MC \& Holness MJ 2003 Recent advances in mechanisms regulating glucose oxidation at the level of the pyruvate dehydrogenase complex by PDKs. American Journal of Physiology. Endocrinology and Metabolism 284 E855-E862. (doi:10.1152/ajpendo.00526.2002)

Sugden MC, Zariwala MG \& Holness MJ 2009 PPARs and the orchestration of metabolic fuel selection. Pharmacological Research 60 141-150. (doi:10.1016/j.phrs.2009.03.014)

Tsintzas K, Jewell K, Kamran M, Laithwaite D, Boonsong T, Littlewood J, Macdonald I \& Bennett A 2006 Differential regulation of metabolic genes in skeletal muscle during starvation and refeeding in humans. Journal of Physiology 575 291-303. (doi:10.1113/jphysiol.2006.109892)

Tsintzas K, Chokkalingam K, Jewell K, Norton L, Macdonald IA \& Constantin-Teodosiu D 2007 Elevated free fatty acids attenuate the insulin-induced suppression of PDK4 gene expression in human skeletal muscle: potential role of intramuscular long-chain acyl-coenzyme A. Journal of Clinical Endocrinology and Metabolism 92 3967-3972. (doi:10.1210/jc.2007-1104)

Wall BT, Stephens FB, Constantin-Teodosiu D, Marimuthu K, Macdonald IA \& Greenhaff PL 2011 Chronic oral ingestion of L-carnitine and carbohydrate increases muscle carnitine content and alters muscle fuel metabolism during exercise in humans. Journal of Physiology $\mathbf{5 8 9}$ 963-973. (doi:10.1113/jphysiol.2010.201343)

Warner A, Jethwa PH, Wyse CA, I'Anson H, Brameld JM \& Ebling FJ 2010 Effects of photoperiod on daily locomotor activity, energy expenditure, and feeding behavior in a seasonal mammal. American Journal of Physiology. Regulatory, Integrative and Comparative Physiology 298 R1409-R1416. (doi:10.1152/ajpregu.00279.2009)

Wende AR, Huss JM, Schaeffer PJ, Giguere V \& Kelly DP 2005 PGC- $1 \alpha$ coactivates PDK4 gene expression via the orphan nuclear receptor $E R R \alpha$ : a mechanism for transcriptional control of muscle glucose metabolism. Molecular and Cellular Biology 25 10684-10694. (doi:10.1128/MCB.25.24.10684-10694.2005)

Received in final form 28 July 2015

Accepted 18 August 2015

Accepted Preprint published online 20 August 2015 http://joe.endocrinology-journals.org DOI: $10.1530 / J O E-15-0334$
() 2015 Society for Endocrinology Printed in Great Britain
Published by Bioscientifica Ltd. 